\title{
Predictive factors for pacemaker requirement after transcatheter aortic valve implantation
}

 \\ Gökmen Turan', Dietmar Bänsch', Olga Thiele1, Dimitar Divchev', Ilkay Bozdag-Turan', Jasmin Ortak1, \\ Gunther Kundt ${ }^{2}$, Christoph A Nienaber ${ }^{1}$ and Hüseyin Ince ${ }^{1}$
}

\begin{abstract}
Background: Transcatheter aortic valve implantation (TAVI) has been established as a treatment option for inoperable patients with symptomatic aortic valve stenosis. However, patients suffer frequently from conduction disturbances after TAVI.

Methods: Baseline, procedural as well as surface and intracardiac ECG parameters were evaluated for patients treated with TAVI and a comparison between patients requiring pacemaker with those not suffering from relevant conduction disorders were done.

Results: TAVI was successfully in all patients $(n=45)$. Baseline surface and intracardiac ECG recording revealed longer PQ (197.1 $\pm 51.2 \mathrm{msec}$ versus 154.1 $\pm 32.1 \mathrm{msec} ; \mathrm{p}<0.001)$, longer AH (153.6 $\pm 43.4 \mathrm{msec}$ versus $116.1 \pm 31.2 \mathrm{msec}$; $p<0.001)$ and $H V$ interval $(81.7 \pm 17.8$ msec versus $56.8 \pm 8.5$ msec; $p<0.001)$ in patients with need for a pacemaker $(n=23)$ versus control group $(n=22)$; furthermore, 7-day follow-up analysis showed a higher prevalence of new left bundle branch block (LBBB) $(87.0 \%$ versus 31.9\%; $\mathrm{p}<0.001)$. Multivariate analysis revealed that only new $L B B B, Q R S$ duration $>120$ msec and a PQ interval $>200$ msec immediately (within 60 minutes) after implantation of the aortic valve were predictors for high-grade (type II second-degree and third-degree) AV block. Other clinical parameters as well as baseline electrocardiographic parameters had no impact on critical conduction delay.

Conclusion: Cardiac conduction disturbances are common after TAVI. The need for pacing after TAVI is predictable by surface ECG evaluation immediately (within 60 minutes) after the procedure.
\end{abstract}

Keywords: TAVI, AV block, Left bundle branch block, Pacemaker, His bundle

\section{Background}

Transcatheter aortic valve implantation (TAVI) has emerged as an alternative to open surgery in patients with symptomatic aortic valve stenosis considered at high risk or unsuitable for thoracotomy [1,2]. Atrioventricular (AV) block with subsequent pacemaker requirement was described in $6 \%$ of cases after surgical aortic valve replacement, but varies after TAVI between $5.7 \%$ and $42.5 \%$, while new left bundle branch block (LBBB) occurs in up to 50-70\% [2-6]. Moreover, early prediction of pacemaker requirement after TAVI would be of

\footnotetext{
* Correspondence: ibrahim.akin@med.uni-rostock.de

'Heart Center Rostock, Department of Internal Medicine I, University Hospital Rostock, Rostock School of Medicine, Ernst-Heydemann-Str. 6, Rostock 18057, Germany

Full list of author information is available at the end of the article
}

potential benefit by shortening both postoperative monitoring and hospitalization. We compared both clinical parameters as well as surface and intracardiac ECG recordings prior and after TAVI and analyzed differences in patients eventually requiring permanent pacing after TAVI for relevant conduction delay.

\section{Methods \\ Patients}

In our retrospective analysis, between January 2007 and January 200845 patients without previously known pacemaker who underwent TAVI using the third-generation percutaneous self-expanding CoreValve prosthesis (Medtronic Inc; Minneapolis, USA) were identified for this analysis. The criteria for inclusion and exclusion to the TAVI procedure have been described elsewhere [1-4].

\section{Ciomed Central}


In brief, patients were included with echocardiographic measurements of severe native valvular stenosis and an area $<1 \mathrm{~cm}^{2}$, or $<0.6 \mathrm{~cm}^{2} / \mathrm{m}^{2}$ regardless of adjunct valvular regurgitation; a diameter of basal orifice of the stenosed valve between 20 and $27 \mathrm{~mm}$; and a diameter at the sinutubular junction $\leq 43 \mathrm{~mm}$. Most importantly, all patients were considered unfit for open surgery with an EuroSCORE $\geq 20 \%$ [7]. TAVI was suggested in agreement between a cardiac surgeon and both, a clinical and interventional cardiologist; patient's or referring physician`s preference was not relevant $[8,9]$. Treatment strategy was in compliance with the Helsinki Declaration. Our local ethics committee approved this treatment strategy. Patients gave informed consent prior TAVI. Pacemaker implantation at follow-up was considered indicated in case of complete AV-block, type II second-degree AV block, and in presence of new LBBB in combination with $\mathrm{HV}$ prolongation $\geq 75 \mathrm{msec}$. We compared patients requiring a new pacemaker within 7 days with those not requiring any pacemaker and no significant conduction delay after TAVI.

\section{Procedure}

Details of the implantation technique have been described elsewhere [1-4]. In brief, all procedures were performed in an interventional hybrid suite under general anaesthesia to assure stable hemodynamic and minimize patient movement. TAVI was performed via femoral access under fluoroscopy; the aortic valve was initially dilated using a standard valvuloplasty balloon with a nominal diameter similar to the aortic valve and followed by CoreValve (Medtronic Inc.) insertion [1,3-6]. In each patient, prior to TAVI and aside a right ventricular bipolar pacing lead (Pacel ${ }^{\mathrm{m}}$, St. Jude Medical, St Paul, MN, USA), a 6F quadripole electrode catheter with ring electrodes (5-mm interpole distance) (Webster $\mathrm{D}^{\mathrm{m}}$, Biosense Webster, Diamond, USA) was introduced and advanced to the His bundle. A $6 \mathrm{~F}$ quadripolar electrode catheter (Soloist ${ }^{\mathrm{m}}$, Medtronic, Minneapolis, MN, USA) was advanced to the right atrium and another to the right ventricle to record a bipolar electrogram and for programmed atrial and ventricular stimulation. The access sites for all electrophysiologic electrode catheters were the femoral veins. With such instrumentation the sinus node recovery time (SNRT), corrected sinus node recovery time (cSNRT), antegrade and retrograde effective refractory period (ERP) of the AV node, as well as intracardiac conduction times (atrium to $\mathrm{His}$ and $\mathrm{His}$ to ventricle time; $\mathrm{AH}$ and $\mathrm{HV}$ interval) were assessed. The rational to measure SNRT was the observations of sinus node arrest in a single patient receiving a CoreValve prior this study. Thus, we wanted to avoid oversee sinus node pathology in this elderly patients suffering from a high comorbidity index. All measurements were done on an Axiom Sensis ${ }^{\mathrm{Tm}}$ (Siemens, Erlangen, Germany) electrophysiology workstation prior to the valve implantation, immediately after valve implantation and at a follow-up of 7 days. The AV nodal ERP was measured by introducing a single extrastimulus (S2) after a drive train of 8 stimuli at a fixed rate (S1) (600ms), at which time the S1-S2 interval is decreased until the S2 impulse does not conduct to the His bundle. To assess conduction disorders, patients were attached to uninterrupted ECG monitoring using the Philips monitoring system (IntelliVue ${ }^{\mathrm{Tm}}$, Best, The Netherlands) that is installed at our ICU/IMC unit. All patients were prophylactically given a temporary pacemaker via the existing femoral venous access; with VVI mode the active pacing was $60 \mathrm{bpm}$ for at least 24 hours.

\section{Statistical methods}

All data were stored and analysed using SPSS statistical package 17.0 (Chicago, Illinois, USA). The statistics computed included mean and standard deviations of continuous variables and are presented as means \pm SD, frequencies and relative frequencies of categorical factors. The Fisher exact test and $\mathrm{chi}^{2}$-test were used to compare proportions. A normal distribution of differences was confirmed by the Kolmogorov-Smirnov test; in presence of normally distributed data the t-test was used while with non-normal distribution the MannWhitney U-test was applied. The logistic regression model was used to assess the interdependence of highgrade AV block (type II second-degree and third-degree) at 7 day follow-up from prognostic factors. First, univariate analyses were performed to reveal unadjusted significant associations between prognostic variables and high-grade AV block. Thereafter, variables yielding p-values $\leq 0.25$ with univariate analysis were entered in the multivariate model to assess adjusted associations between outcomes and covariates which were univariate and of borderline significance. All p-values resulted from two-sided statistical tests and $\leq 0.05$ was considered to be significant.

\section{Results}

The analysis included 18 men and 27 women at a mean age of $81.5 \pm 6.8$ years with severe aortic valve stenosis and no previously known pacemaker. All patients had qualified for TAVI following recent recommendations $[8,9]$. We compared patients requiring new pacemaker implantation during hospital stay $(\mathrm{n}=23)$ with those not suffering from relevant conduction delays $(n=22)$ in the attempt to elucidate predictors for pacing. Smokers (34.8\% versus $18.2 \%$; $\mathrm{p}=0.024$ ) as well as patients suffering from angina, with ischemic heart disease, previous stroke or peripheral arterial disease were more frequent 
in the pacemaker group. Moreover, logistic EuroSCORE operative mortality estimate was higher in patients requiring a pacemaker compared to the non-pacemaker group $(24.0 \pm 14.6 \%$ versus $18.4 \pm 19.2 \%$; $\mathrm{p}=0.034)$. Echocardiographic measurements on aortic stenosis severity and left ventricular function as well as intraoperative data revealed similar findings in both groups (Table 1).

TAVI was successfully performed in all patients with a mean procedural time of $107.7 \pm 27.1 \mathrm{~min}$ and $104.9 \pm 33.3$ $\min (\mathrm{p}=0.725)$; length of stay in intensive care unit and in-hospital stay was similar in both groups. Six patients suffered from intraprocedural circulatory depression and required transient intravenous pressors; 1 patient required $1 \mathrm{DC}$ shock for ventricular fibrillation during wire navigation of the calcified aortic stenosis. Postinterventional aortography revealed similar grades of aortic insufficiency (Table 2).

The incidence of conduction delay requiring pacemaker implantation during 7-day follow-up after TAVI was $51.1 \%(\mathrm{n}=23)$ due to complete AV block in $13.3 \%$ $(n=6)$, type II second-degree AV block in $8.9 \%(n=4)$ and due to combined new LBBB with prolongation of HV interval $\geq 75 \mathrm{msec}$ in $28.8 \%(\mathrm{n}=13)$ (Table 3) (Figure 1). Baseline surface and intracardiac ECG recording revealed longer PQ interval of $197.1 \pm 51.2 \mathrm{msec}$ versus $154.1 \pm 32.1$ msec $(\mathrm{p}<0.001)$ caused by longer $\mathrm{AH}$ and HV intervals in the pacemaker group (Figure 2). Evaluation within 60 minutes after TAVI and at 7-day post TAVI, which was done in all patients, revealed a higher prevalence of new LBBB in pacemaker group with $87.0 \%$ versus $31.9 \%(p<0.001)$, as well as longer intervals for $\mathrm{PQ}, \mathrm{AH}$ and $\mathrm{HV}$ interval $(\mathrm{p}<0.001)$. Similarly, QRS duration and antegrade and retrograde ERP were higher in pacemaker group $(\mathrm{p}<0.001)$ without any differences in SNRT or rates of right bundle branch block. Of 22 patients suffering from first-degree AV block 18 demonstrated prolonged HV interval (13 patients with a prolongation to $\geq 75 \mathrm{msec}$ and 5 with a prolongation to $<75 \mathrm{msec}$ ), while 8 patients revealed a prolongation of $\mathrm{AH}$ interval without progression to complete heart block. Similarly, 5 patients with prolongation of HV interval to $<75$ msec received no pacemaker (Table 3).

A multivariate analysis to identify predictors for highgrade AV block (type II second-degree and third-degree) resulting in pacemaker requirement included baseline clinical, electrocardiographic and echocardiographic parameters. With evolution to high-grade AV block as a hard endpoint in this model the univariate analysis revealed new LBBB immediately (within 60 minutes) after TAVI (OR 7.67; 95\% CI 1.40-41.94; $\mathrm{p}=0.01$ ), as well as PQ interval > $200 \mathrm{msec}$ (OR 14.00; 95\% CI 1.51130.01; $\mathrm{p}=0.02$ ) and $\mathrm{QRS}$ duration $>120 \mathrm{msec}$ (OR 13.80; 95\% CI 1.535-118.69; $\mathrm{p}=0.019$ ) as predictors for high-grade AV block during hospital stay. Similarly, the
Table 1 Baseline characteristics of study population stratified in pacemaker (PM) and non pacemaker group (N-PM)

\begin{tabular}{lccc}
\hline & $\begin{array}{c}\text { PM } \\
(\mathbf{n = 2 3 )}\end{array}$ & $\begin{array}{c}\text { N-PM } \\
(\mathbf{n = 2 2})\end{array}$ & $\mathbf{p}$ \\
\hline & Clinical parameters & & \\
\hline Male, $\mathrm{n}(\%)$ & $10(43.5)$ & $8(36.4)$ & 0.763 \\
\hline Age $(\mathrm{yrs})$ & $80.7 \pm 5.94$ & $81.55 \pm 7.90$ & 0.684 \\
\hline Body mass index $\left(\mathrm{kg} / \mathrm{m}^{2}\right)$ & $26.9 \pm 3.9$ & $26.8 \pm 4.0$ & 0.883 \\
\hline Hypertension, $\mathrm{n}(\%)$ & $22(95.7)$ & $19(86.4)$ & 0.346 \\
\hline Smoker, $\mathrm{n}(\%)$ & $8(34.8)$ & $4(18.2)$ & 0.024 \\
\hline Diabetes mellitus, $\mathrm{n}(\%)$ & $10(43.5)$ & $7(31.8)$ & 0.542 \\
\hline Creatinine $(\mu \mathrm{mol} / \mathrm{l})$ & $151.2 \pm 157.4$ & $114.3 \pm 51.6$ & 0.372 \\
\hline $\begin{array}{l}\text { Renal insufficiency } \\
\text { (creatinine level }>\text { 1.5mg/dl), } \\
\mathrm{n}(\%)\end{array}$ & $14(60.9)$ & $11(50)$ & 0.554 \\
\hline
\end{tabular}
n (\%)

\begin{tabular}{llll}
\hline $\begin{array}{l}\text { Chronic obstructive } \\
\text { pulmonary disease, } \mathrm{n}(\%)\end{array}$ & $4(17.1)$ & $4(18.2)$ & 0.855 \\
\hline
\end{tabular}

New York Heart Association functional class

\begin{tabular}{lccc}
\hline & $0(0)$ & $0(0)$ & 0.263 \\
\hline III & $0(0)$ & $2(9.1)$ & \\
\hline IV & $15(65.2)$ & $15(68.2)$ & \\
\hline Logistic EuroSCORE (\%) & $8(34.8)$ & $5(22.7)$ & \\
\hline Dyspnoe, $\mathrm{n}(\%)$ & $24.0 \pm 14.6$ & $18.4 \pm 19.2$ & 0.034 \\
\hline Angina, $\mathrm{n}(\%)$ & $13(56.6)$ & $12(54.6)$ & 0.628 \\
\hline Syncope, $\mathrm{n}(\%)$ & $11(47.5)$ & $6(27.3)$ & 0.022 \\
\hline Pulmonal artery pressure $(\mathrm{mmHg})$ & $42.8 \pm 17.7$ & $37.6 \pm 19.9$ & 0.375 \\
\hline Porcelain aorta, $\mathrm{n}(\%)$ & $1(4.3)$ & $3(13.6)$ & 0.346 \\
\hline Prior cardiac decompensation, $\mathrm{n}(\%)$ & $13(56.5)$ & $14(63.7)$ & 0.763 \\
\hline Ischemic heart disease, $\mathrm{n}(\%)$ & $20(87.0)$ & $15(68.2)$ & 0.017 \\
\hline Previous stroke, $\mathrm{n}(\%)$ & $10(43.5)$ & $3(13.6)$ & 0.047 \\
\hline Previous CABG, $\mathrm{n}(\%)$ & $1(4.3)$ & $2(9.1)$ & 0.838 \\
\hline Peripheral vessel disease, $\mathrm{n}(\%)$ & $5(21.7)$ & $1(4.6)$ & 0.002 \\
\hline
\end{tabular}

\begin{tabular}{lccc}
\multicolumn{4}{c}{ Echocardiographic parameters } \\
\hline Mean aortic valve area $\left(\mathrm{cm}^{2}\right)$ & $0.8 \pm 0.2$ & $0.7 \pm 0.2$ & 0.108 \\
\hline Left ventricular ejection & $46.1 \pm 10.7$ & $50.2 \pm 12.5$ & 0.224
\end{tabular}

fraction (\%)

\begin{tabular}{lccc}
\hline Peak pressure gradient $(\mathrm{mmHg})$ & $90.6 \pm 24.1$ & $86.6 \pm 27.9$ & 0.641 \\
\hline Mean pressure gradient $(\mathrm{mmHg})$ & $57.7 \pm 15.3$ & $55.4 \pm 15.6$ & 0.674 \\
\hline Aortic annulus dimension $(\mathrm{mm})$ & $23.30 \pm 5.32$ & $22.36 \pm 6.85$ & 0.141 \\
\hline Aortic bulbus dimension $(\mathrm{mm})$ & $29.70 \pm 5.86$ & $28.61 \pm 7.46$ & 0.893 \\
\hline $\begin{array}{l}\text { Interventricular septal } \\
\text { dimension }(\mathrm{mm})\end{array}$ & $14.17 \pm 3.82$ & $13.55 \pm 2.46$ & 0.627 \\
\hline Aortic regurgitation grade $\geq \mathrm{I}, \mathrm{n}(\%)$ & $19(82.6)$ & $20(90.9)$ & 0.692 \\
\hline Mitral insufficiency $\geq$ grade $\mathrm{I}, \mathrm{n}(\%)$ & $22(95.7)$ & $19(86.4)$ & 0.247 \\
\hline
\end{tabular}

multivariate model revealed new LBBB immediately (within 60 minutes) after TAVI (OR 24.85; 95\% CI 1.57392.57; $\mathrm{p}=0.023$ ), as well as PQ interval $>200$ msec (OR 11.37; 95\% CI 1.138-97.620; $\mathrm{p}=0.02$ ) and $\mathrm{QRS}>120$ msec (OR 14.28; 95\% CI 1.50-135.88; $\mathrm{p}=0.021$ ) as 
Table 2 Intraoperative data of pacemaker (PM) and non pacemaker group (N-PM)

\begin{tabular}{lccc}
\hline & PM & N-PM & p \\
\hline Procedural success, $\mathrm{n}(\%)$ & $23(100)$ & $22(100)$ & 0.999 \\
\hline Conversion to surgical AVR, $\mathrm{n}(\%)$ & $0(0)$ & $0(0)$ & 0.999 \\
\hline $\begin{array}{lccc}\text { Intraprocedural circulatory } \\
\text { depression, } \mathrm{n}(\%)\end{array}$ & $4(17.4)$ & $2(9.1)$ & 0.635 \\
\hline Catecholamine therapy, $\mathrm{n}(\%)$ & $4(17.4)$ & $2(9.1)$ & 0.714 \\
\hline Resuscitation, $\mathrm{n}(\%)$ & $1(4.4)$ & $0(0)$ & 0.553 \\
\hline Defibrillation, $\mathrm{n}(\%)$ & $1(4.4)$ & $0(0)$ & 0.612 \\
\hline $\begin{array}{l}\text { Vascular access site } \\
\text { complication, } \mathrm{n}(\%)\end{array}$ & $5(21.8)$ & $4(18.2)$ & 0.367 \\
\hline Contrast agent (ml) & $113.3 \pm 36.4$ & $125.5 \pm 60.8$ & 0.732 \\
\hline Fluoroscopy time (min) & $25.7 \pm 1.8$ & $23.9 \pm 2.6$ & 0.572 \\
\hline Procedure time (min) & $107.7 \pm 27.1$ & $104.9 \pm 33.3$ & 0.725 \\
\hline CoreValve, $\mathrm{n}(\%)$ & & & \\
\hline 26mm & $10(43.5)$ & $12(54.6)$ & 0.112 \\
\hline 29mm & $13(56.6)$ & $10(45.5)$ & 0.386 \\
\hline Pre TAVl, $\mathrm{n}$ (\%) & $23(100)$ & $22(100)$ & 0.999 \\
\hline Post TAVI valvuloplasty, $\mathrm{n}(\%)$ & $10(43.5)$ & $10(45.5)$ & 0.566 \\
\hline Number of inflations, $\mathrm{n}(\%)$ & $1.08 \pm 0.75$ & $1.14 \pm 0.94$ & 0.335 \\
\hline Balloon diameter (mm) & $21.87 \pm 3.84$ & $21.27 \pm 4.44$ & 0.432 \\
\hline Balloon length (mm) & $55.22 \pm 26.81$ & $52.73 \pm 30.27$ & 0.613 \\
\hline Angiographic Aortic & $1.22 \pm 0.48$ & $1.10 \pm 0.62$ & 0.725 \\
insufficiency (grade) & $2.9 \pm 3.2$ & $2.5 \pm 1.8$ & 0.686 \\
\hline ICU stay (days) & $13.4 \pm 11.3$ & $12.0 \pm 6.5$ & 0.237 \\
\hline Hospital stay (days) & & & \\
\hline & & & \\
\hline
\end{tabular}

predictors for high-grade AV block. Other clinical parameters as well as baseline electrocardiographic parameters (e.g. AH interval $>100 \mathrm{~ms}$, HV interval $>75 \mathrm{~ms}$, QRS $>120 \mathrm{~ms}$ and PQ $>200 \mathrm{~ms}$ ) had no impact to predict critical conduction delay (Tables 1, 2, 3).

\section{Discussion}

TAVI is established as an option with reduced morbidity and mortality in high risk symptomatic patients unfit for open surgery [10-14]. Considering the proximity of aortic valve annulus to conduction system, both open surgery and TAVI may impact on both AV node and His bundle conduction.

While complete AV block was reported in 5.7\%, new LBBB occurred in $18 \%$ with an association to complete AV block, syncope, and sudden cardiac arrest at long term after open surgery [15-17]. Risk factors for complete AV block after surgical aortic valve replacement include previous aortic regurgitation, myocardial infarction, pulmonary hypertension, and postoperative electrolyte imbalance [16,17], among ECG criteria right bundle branch block (RBBB) on surface ECG was the strongest predictor for pacemaker requirement $[16,17]$.
Although previous investigations report changes in surface-ECG after TAVI [2,10-14], our group was the first to describe intracardiac conduction abnormalities for better discrimination of new ECG changes on surface-ECG, and to predict critical conduction delays [18]. In our series, complete AV block was seen in 13.3\%,

\section{Table 3 Electrocardiographic characteristics}

\begin{tabular}{|c|c|c|c|}
\hline & Prior TAVI & After TAVI & $\begin{array}{c}\text { 7-day } \\
\text { follow-up }\end{array}$ \\
\hline \multicolumn{4}{|c|}{ Rhythm } \\
\hline \multirow[t]{2}{*}{ Sinus } & $18(78.3)$ & $18(78.3)$ & $14(63.7)$ \\
\hline & $20(91.0)$ & $20(91.0)$ & $19(82.7) *$ \\
\hline \multirow[t]{2}{*}{ Atrial fibrillation } & $5(21.8)$ & $5(21.8)$ & $5(21.8)$ \\
\hline & $2(9.1)$ & $2(9.1)$ & $5(9.1)$ \\
\hline \multirow[t]{2}{*}{ Heart rate } & $72.7 \pm 12.6$ & $68.5 \pm 13.8$ & $66.0 \pm 16.9$ \\
\hline & $67.5 \pm 10.5$ & $63.2 \pm 14.4$ & $65.7 \pm 13.1$ \\
\hline \multicolumn{4}{|c|}{ Surface ECG } \\
\hline \multirow[t]{2}{*}{ PQ interval } & $197.1 \pm 51.2$ & $230.42 \pm 40.94$ & $243.05 \pm 34.59$ \\
\hline & $154.1 \pm 32.1 *$ & $167.37 \pm 37.05 *$ & $168.56 \pm 30.41 *$ \\
\hline \multirow[t]{2}{*}{ QRS width } & $97.0 \pm 15.0$ & $139.04 \pm 31.86$ & $162.96 \pm 33.59$ \\
\hline & $95.3 \pm 14.4$ & $110.27 \pm 18.38 *$ & $120.00 \pm 24.17 *$ \\
\hline \multirow[t]{2}{*}{ QT interval } & $388.2 \pm 29.3$ & $409.91 \pm 28.67$ & $408.52 \pm 23.22$ \\
\hline & $398.6 \pm 32.8$ & $407.36 \pm 32.99$ & $405.14 \pm 32.03$ \\
\hline \multirow[t]{2}{*}{ Left-BBB } & $0(0)$ & $16(69.6)$ & $20(87.0)$ \\
\hline & $1(4.5)$ & $4(18.2) *$ & $7(31.9) *$ \\
\hline \multirow[t]{2}{*}{ Right-BBB } & $1(4.35)$ & $0(0)$ & $0(0)$ \\
\hline & $1(4.5)$ & $1(4.6)$ & $1(4.6)$ \\
\hline \multirow{2}{*}{$\begin{array}{l}\text { First-degree } \\
\text { block }\end{array}$} & $5(21.8)$ & $8(34.8)$ & $18(78.3)$ \\
\hline & $3(13.7) *$ & $3(13.7) *$ & $4(18.2) *$ \\
\hline \multirow{2}{*}{$\begin{array}{l}\text { Second-degree } \\
\text { block \# }\end{array}$} & $0(0)$ & $4(17.4)$ & $4(17.4)$ \\
\hline & $0(0)$ & $0(0) *$ & $0(0) *$ \\
\hline \multirow{2}{*}{$\begin{array}{l}\text { Complete } \\
\text { block }\end{array}$} & $0(0)$ & $4(17.4)$ & $6(26.1)$ \\
\hline & $0(0)$ & $0(0) *$ & $0(0) *$ \\
\hline \multicolumn{4}{|c|}{ Intracardiac measurement } \\
\hline \multirow[t]{2}{*}{$\overline{\text { SNRT }}$} & $1086.8 \pm 171.2$ & $1093.89 \pm 154.58$ & $1122.11 \pm 154.47$ \\
\hline & $1045.6 \pm 166.9$ & $1050.56 \pm 163.40$ & $1070.59 \pm 154.13$ \\
\hline \multirow[t]{2}{*}{ C-SNRT } & $487.0 \pm 54.3$ & $492.94 \pm 43.88$ & $498.13 \pm 42.72$ \\
\hline & $462.0 \pm 68.4$ & $491.12 \pm 42.04$ & $488.59 \pm 42.48$ \\
\hline \multirow[t]{2}{*}{$\overline{\mathrm{AH}}$ interval } & $135.5 \pm 44.7$ & $139.32 \pm 36.62$ & $153.61 \pm 43.40$ \\
\hline & $105.8 \pm 31.4^{*}$ & $114.50 \pm 38.55 *$ & $116.06 \pm 31.23 *$ \\
\hline \multirow[t]{2}{*}{$\mathrm{HV}$ interval } & $58.5 \pm 12.5$ & $74.00 \pm 13.51$ & $81.68 \pm 17.76$ \\
\hline & $48.7 \pm 6.9 *$ & $55.27 \pm 9.20 *$ & $56.76 \pm 8.45 *$ \\
\hline \multirow{2}{*}{$\begin{array}{l}\text { Antegrade } \\
\text { AV ERP }\end{array}$} & $410.0 \pm 42.6$ & $470.00 \pm 118.57$ & $469.81 \pm 45.75$ \\
\hline & $394.4 \pm 32.6$ & $407.78 \pm 32.64 *$ & $414.71 \pm 31.45 *$ \\
\hline \multirow{2}{*}{$\begin{array}{l}\text { Retrograde } \\
\text { AV ERP }\end{array}$} & $442.6 \pm 38.0$ & $470.56 \pm 45.10$ & $494.00 \pm 59.33$ \\
\hline & $420.0 \pm 34.3$ & $436.67 \pm 35.48 *$ & $441.76 \pm 36.27 *$ \\
\hline
\end{tabular}

* p-value $<0.05$.

italic : N-PM-group.

normal: PM-group.

$\# 2^{\text {nd }}$ degree (type 2 ) AV-block. 


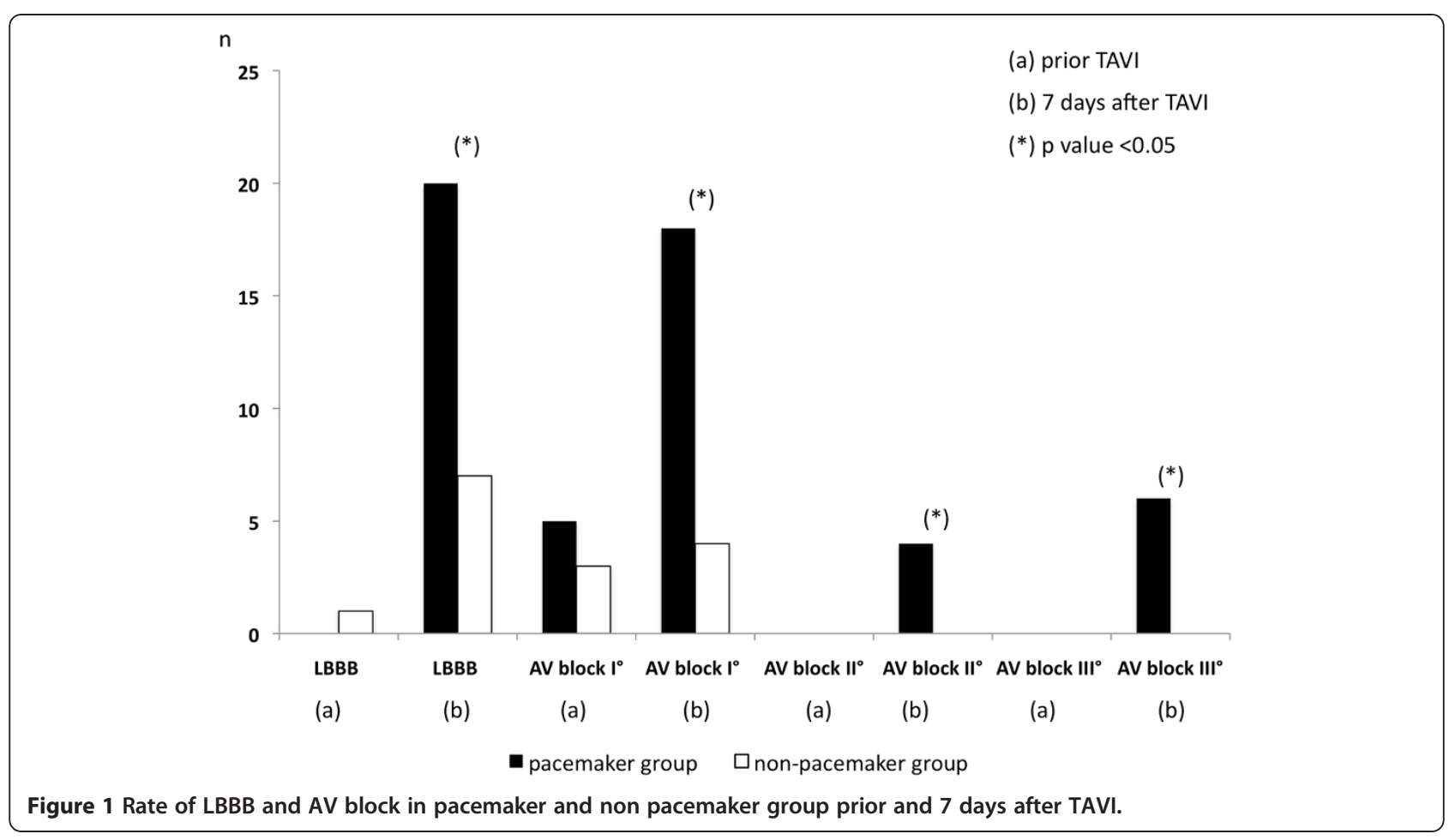

while $8.9 \%$ suffered from type II second-degree AV block; thus, $22.2 \%$ of patients developed an indication for permanent pacemaker implantation corroborating previous findings [10-14,19-23]. Additionally, 28.9\% patients received a pacemaker for new LBBB combined with a marked prolongation of the $\mathrm{HV}$ interval to $\geq 75$ msec for primary prevention. Such indication may be debatable, but due to the lack of data and due to the

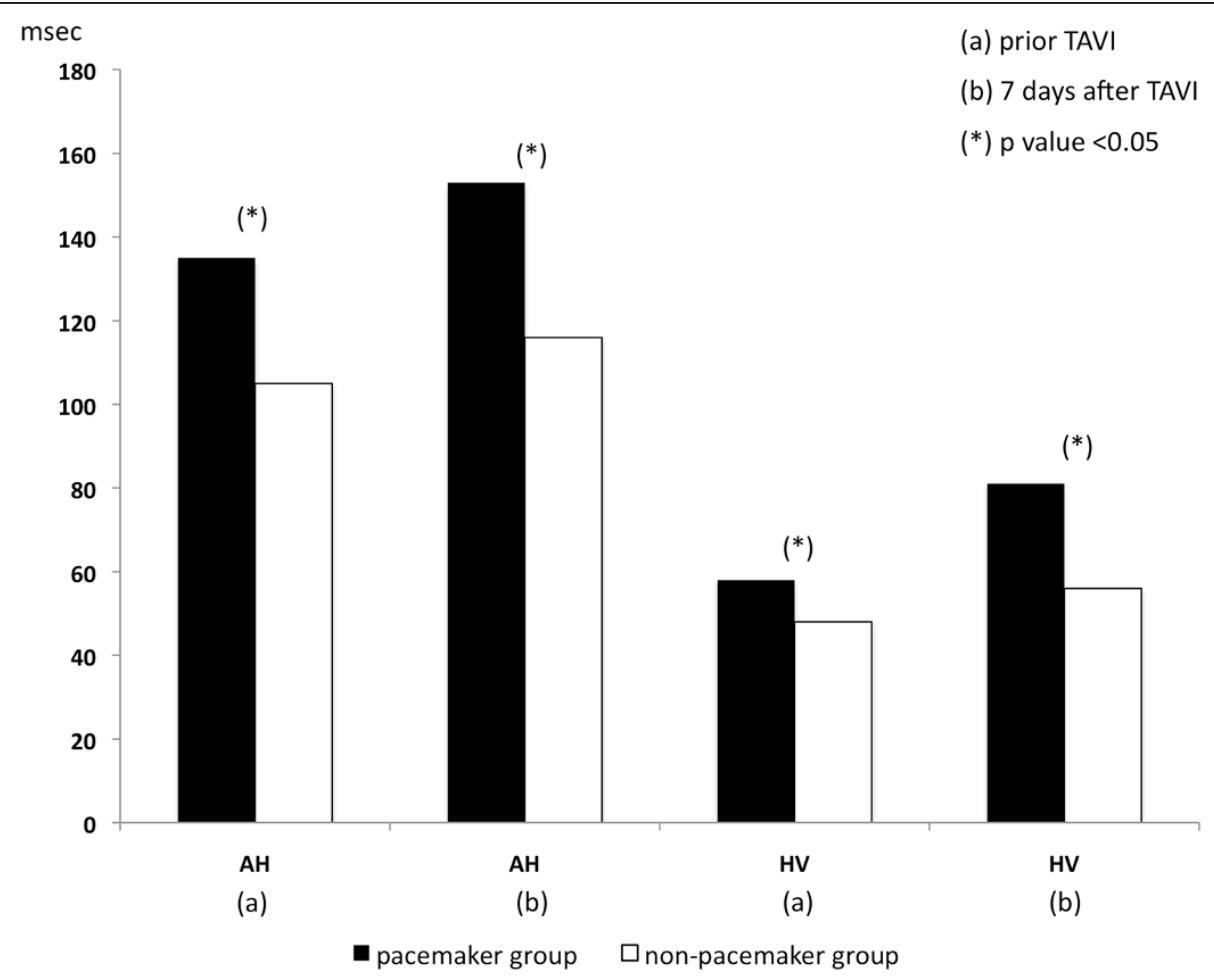

Figure $2 \mathrm{AH}$ and HV conduction time in pacemaker and non pacemaker group prior and 7 days after TAVI. 
novelty of TAVI in elderly patients with several comorbidities preventive pacemaker use appears justified [24].

Jilaihawi et al. reported first that pacemaker requirement after TAVI correlates to left axis deviation at baseline, LBBB, baseline thickness of the native noncoronary cusp and to diastolic interventricular septal dimension $>17 \mathrm{~mm}$ [13]. Similarly, Piazza et al. revealed no prosthesis-related $\mathrm{LBBB}$ when the proximal end of the valve frame was positioned $<6.7 \mathrm{~mm}$ from the lower edge of the non-coronary cusp [10]. Degenerative calcification of the aortic and mitral annulus is probably a diffuse process, in which the cardiac conduction system is often involved and making it vulnerable to injury when exposed to mechanical compression by the nitinol frame of the CoreValve, which seems to completely expand within the first 710 days [14]. Differences to surgical aortic valve replacement might be due to the different techniques. In surgical approach the valve is replaced by another. Thus, the amount of conduction damage is predictable because the local trauma is nearly the same in all patients. However, in TAVI the amount of local damage is dependent of local calcification, the height of implantation in LVOT, the extend of trauma during index-procedure (balloon valvuloplasty, balloonto-aortic annulus relation, post-TAVI dilatation) and from further aortic annulus geometry.

Our intracardiac measurements revealed that occurrence of first-degree AV block were predominantly due to prolongation of $\mathrm{HV}$ interval, which might be prognostically relevant [24]. We implanted pacemaker in patients with new LBBB and a HV prolongation to $\geq 75$ msec in a somewhat liberal fashion in this patients with high comorbidity index. In contrast, our multivariate analysis revealed that only a PQ duration $>200 \mathrm{msec}$, a LBBB and a QRS duration $>120$ msec immediately (within 60 minutes) after CoreValve implantation seem to predict critical AV conduction delay. Other baseline clinical and ECG parameters had no impact. The occurrence of above ECG findings soon after TAVI may reflect the extent of trauma from the procedure. Interestingly, the exact determination of both the amount of valve calcification and the height of implantation turned out to be non-reproducible although both parameters have been claimed to impact on conduction physiology [10,13]. For example, the Edwards SAPIEN valve, shorter and less likely to extend into the left ventricular outflow tract, is obviously associated with a lower rate of complete AV block (0-6\%) [25,26]. As demonstrated by our results, we believe that regardless of favourable anatomy only the extent of trauma predict the occurrence of critical conduction delay after TAVI. According to our multivariate analysis HV prolongation $\geq 75 \mathrm{msec}$ is not a predictor for pacemaker requirement. We have implanted since 2007 nearly 400 aortic valves. Our pacemaker rate was initially about $45 \%$. This was due to the novelty of this technique and lack of information regarding the true indication for pacing. However, with further analysis of patients and improving implantation techniques (e.g. high implantation technique, no further post-TAVI balloon dilatation) our pacing rate decreased to $9-10 \%$. Based on our data we decided not to perform routinely intracardiac measurements. The presence of a new left bundle branch block in case of normal AV conduction on surface ECG in not an indication for pacing. For clinical routine, a surface 12-lead ECG immediately (within 60 minutes) after the TAVI procedure may indicate the need for pacemaker without incremental information from intracardiac ECG recordings, the quantification of aortic valve calcification, septal thickness or height of implantation.

\section{Conclusion}

TAVI is feasible and safe in patients unfit for open surgical aortic valve replacement. Due to the proximity of the implanted valve structure to the septum, conduction disturbances are common after TAVI requiring close surveillance at least for 7 days after TAVI. The occurrence of complete and type II second-degree AV block is predictable by a new LBBB, a PQ duration $>200 \mathrm{msec}$ and QRS duration $>120 \mathrm{msec}$ soon after TAVI and reflect the extent of trauma to the conduction system. Yet, the occurrence of new LBBB combined with first-degree AV block, reflecting prolongation of the HV interval, is frequent and should be subjected to further study.

\section{Study limitation}

The present study suffers from the limitation of being a retrospective analysis. Additionally, the low number of patients may influence the results. However, our study showed that there might be no further information from intracardiac measurements as the ECG changes predominantly present as LBBB, first grade and complete AV block. The differentiation of AV block in supra-His and infra-His is not essential in these frailty patients with high comorbidity index. Thus, there will always be a somewhat "liberal" indication for pacemaker implantation. To date, there is a need for further larger scale prospective trials as well as registries with longer followup for predicting factors for pacemaker requirement and defining the role and duration of ECG changes.

\section{Abbreviations}

AS: Aortic stenosis; AVA: Aortic valve area; AVR: Aortic valve replacement; c-SNRT: Corrected sinus node recovery time; ECG: Electrocardiography; ERP: Effective refractory period; ICU: Intensive care unit; IMC: Intermediate care; LBBB: Left bundle branch block; NYHA: New York Heart Association; PCI: Percutaneous coronary intervention; SNRT: Sinus node recovery time; TAVI: Transcatheter aortic valve implantation. 


\section{Competing interests}

The authors declare that they have no competing interests.

\section{Authors' contribution}

IA, SK, LP, HS, TCR, UT, RGT, DB, OT, DD, IBT, JO, HI, CAN participate in treating the patients during intervention / ICU and acquisition of data. IA, HI and CAN wrote the manuscript. IA and GK performed the statistical analyses. All authors read and approved the final manuscript.

\section{Author details}

${ }^{1}$ Heart Center Rostock, Department of Internal Medicine I, University Hospital Rostock, Rostock School of Medicine, Ernst-Heydemann-Str. 6, Rostock 18057, Germany. ${ }^{2}$ Institute for Biostatistics and Information in Medicine and Ageing Research, University Hospital Rostock, Rostock School of Medicine, Ernst-Heydemann-Str. 6, Rostock 18057, Germany.

Received: 7 July 2012 Accepted: 28 September 2012

Published: 4 October 2012

\section{References}

1. Makkar RR, Fontana GP, Jilaihawi H, Kapadia S, Pichard AD, Douglas PS, Thourani VH, Babaliaros VC, Webb JG, Herrmann HC, Bavaria JE, Kodali S, Brown DL, Bowers B, Dewey TM, Svensson LG, Tuzcu M, Moses JW, Williams MR, Siegel RJ, Akin JJ, Anderson WN, Pocock S, Leon MB, PARTNER Trial Investigators: Transcatheter aortic-valve replacement for inoperable severe aortic stenosis. N Engl J Med 2012, 366:1696-1704.

2. Kodali SK, Williams MR, Smith CR, Svensson LG, Webb JG, Makkar RR, Fontana GP, Dewey TM, Thourani VH, Pichard AD, Fischbein M, Szeto WY, Lim S, Greason KL, Teirstein PS, Malaisrie SC, Douglas PS, Hahn RT, Whisenant B, Zajarias A, Wang D, Akin JJ, Anderson WN, Leon MB, PARTNER Trial Investigators: N Engl J Med 2012, 366:1686-1695.

3. Zahn R, Gerckens U, Grube E, Linke A, Sievert H, Eggebrecht H, Hambrecht R, Sack S, Hauptmann KE, Richardt G, Figulla HR, Senges J, German Transcatheter Aortic Valve Interventions-Registry Investigators: Transcatheter aortic valve implantation: first results from a multi-centre real-world registry. Eur Heart J 2011, 32:198-204.

4. Grube E, Schuler G, Buellesfeld L, Gerckens U, Linke A, Wenaweser P, Sauren B, Mohr FW, Walther T, Zickmann B, Iversen S, Felderhoff T, Cartier R, Bonan $R$ : Percutaneous aortic valve replacement for severe aortic stenosis in high-risk patients using the second- and current third-generation selfexpanding CoreValve prosthesis: device success and 30-day clinical outcome. J Am Coll Cardiol 2007, 50:69-76.

5. Webb JG, Chandavimol M, Thompson CR, Ricci DR, Carere RG, Munt BI, Buller CE, Pasupati S, Lichtenstein S: Percutaneous aortic valve implantation retrograde from the femoral artery. Circulation 2006, 112:842-850.

6. Bates MG, Matthews IG, Fazal IA, Turley AJ: Postoperative permanent pacemaker implantation in patients undergoing trans-catheter aortic valve implantation: what is the incidence and are there any predicting factors? Interact Cardiovasc Thorac Surg 2001, 12:243-253.

7. Roques F, Nashef SA, Michel P, EuroSCORE Project Group: Risk factors and outcome in European cardiac surgery: analysis of the EuroSCORE multinational database of 19030 patients. Eur J Cardiothorac Surg 1999 15:816-822.

8. Vahanian A, Alfieri O, Al-Attar N, Antunes M, Bax J, Cormier B, Cribrier A, De Jaegere P, Fournial G, Kappetein AP, Kovac J, Ludgate S, Maisano F, Moat N, Mohr F, Nataf P, Piérard L, Pomar JL, Schofer J, Tornos P, Tuzcu M, van Hout $B$, Von Segesser LK, Walther T, European Association of Cardio-Thoracic Surgery; European Society of Cardiology; European Association of Percutaneous Cardiovascular Interventions: Transcatheter valve implantation for patients with aortic stenosis: a position statement from the European Association of Cardio-Thoracic Surgery (EACTS) and the European Society of Cardiology (ESC), in collaboration with the European Association of Percutaneous Cardiovascular Intervention (EAPCI). Eur Heart J 2008, 29:1463-1470.

9. Leon MB, Piazza N, Nikolsky E, Blackstone EH, Cutlip DE, Kappetein AP, Krucoff MW, Mack M, Mehran R, Miller C, Morel MA, Petersen J, Popma JJ, Takkenberg JJ, Vahanian A, van Es GA, Vranckx P, Webb JG, Windecker S, Serruys PW: Standardized endpoint definitions for transcatheter aortic valve implantation clinical trials: a consensus report from the Valve Academic Research Consortium. Eur Heart J 2011, 32:205-217.
10. Piazza N, Onuma $Y$, Jesserun E, Kint PP, Maugenest AM, Anderson RH, de Jaegere PP, Serruys PW: Early and persistent intraventricular conduction abnormalities and requirements for pacemaking after percutaneous replacement of the aortic valve. JACC Cardiovasc Interv 2008, 1:310-316.

11. Baan J Jr, Yong ZY, Koch KT, Henriques JP, Bouma BJ, Vis MM, Cocchieri R, Piek JJ, de Mol BA: Factors associated with cardiac conduction disorders and permanent pacemaker implantation after percutaneous aortic valve implantation with the CoreValve prosthesis. Am Heart J 2010, 159:497-503.

12. Calvi V, Puzzangara E, Pruiti GP, Conti S, Di Grazia A, Ussia GP, Capodanno $D$, Tamburino C: Early conduction disorders following percutaneous aortic valve replacement. Pacing Clin Electrophysio/ 2009, 32(Suppl 1):S126-130.

13. Jilaihawi $H$, Chin D, Vasa-Nicotera M, Jeilan M, Spyt T, Ng GA, Bence J, Logtens $E$, Kovac J: Predictors for permanent pacemaker requirement after transcatheter aortic valve implantation with the CoreValve bioprosthesis. Am Heart J 2009, 157:860-866.

14. Piazza N, Nuis RJ, Tzikas A, Otten A, Onuma Y, Garcia-Garcia H, Schultz C, van Domburg R, van Es GA, van Geuns R, de Jaegere P, Serruys PW: Persistent conduction abnormalities and requirements for pacemaking six months after transcatheter aortic valve implantation. Eurolntervention 2010, 6:475-484.

15. El-Khally Z, Thibault B, Stainloae C, Theroux P, Dubuc M, Roy D, Guerra P, Macle L, Talajic M: Prognostic significance of newly accuired bundle branch block after aortic valve replacement. Am J Cardiol 2004, 94:1008-1011.

16. Marchenese K, Schenk EA: Atrioventricular conduction system lesion following cardiac valve replacement. Circulation 1972, 45-46(Suppl. II):II 188.

17. Koplan BA, Stevenson WG, Epstein LM, Aranki SF, Maisel WH: Development and validation of a simple risk score to predict the need for permanent pacing after cardiac valve surgery. J Am Coll Cardiol 2003, 41:795-801.

18. Akin I, Kische S, Schneider H, Liebold A, Ortak J, Bänsch D, Rehders TC, Thiele O, Schneider R, Kundt G, Krenz H, Chatterjee T, Nienaber CA, Ince H: Surface and intracardiac ECG for discriminating conduction disorders after CoreValve implantation. Clin Res Cardiol 2012, 5:357-364.

19. Fraccaro C, Buja G, Tarantini G, Gasparetto V, Leoni L, Razzolini R, Corrado D, Bonato R, Basso C, Thiene G, Gerosa G, Isabella G, lliceto S, Napodano M: Incidence, predictors, and outcome of conduction disorders after transcatheter self-expandable aortic valve implantation. Am J Cardio/ 2011, 107:747-754.

20. Roten L, Wenaweser P, Delacretaz E, Hellige G, Stortecky S, Tanner H, Pilgrim T, Kadner A, Eberle B, Zwahlen M, Carrel T, Meier B, Windecker S: Incidence and predictors of atrioventricular conduction impairment after transcatheter aortic valve implantation. Am J Cardiol 2010, 106:1473-1480.

21. Ferreira ND, Caeiro D, Adão L, Oliveira M, Gonçalves $H$, Ribeiro J, Teixeira $M$, Albuquerque A, Primo J, Braga P, Simões L, Ribeiro VG: Incidence and predictors of permanent pacemaker requirement after transcatheter aortic valve implantation with self-expanding bioprosthesis. Pacing Clin Electrophysiol 2010, 33:1364-1372.

22. Khawaja MZ, Rajani R, Cook A, Khavandi A, Moynagh A, Chowdhary S, Spence MS, Brown S, Khan SQ, Walker N, Trivedi U, Hutchinson N, De Belder AJ, Moat N, Blackman DJ, Levy RD, Manoharan G, Roberts D, Khogali SS, Crean P, Brecker SJ, Baumbach A, Mullen M, Laborde JC, Hildick-Smith D: Permanent pacemaker insertion after CoreValve transcatheter aortic valve implantation: incidence and contributiong factors (the UK CoreValve Collaborative). Circulation 2011, 123:951-960.

23. Buellesfeld L, Stortecky S, Heg D, Hausen S, Mueller R, Wenaweser P, Pilgrim T, Gloekler S, Khattab AA, Huber C, Carrel T, Eberle B, Meier B, Boekstegers P, Jüni P, Gerckens U, Grube E, Windecker S: Impact of permanent pacemaker implantation on clinical outcome among patients undergoing transcatheter aortic valve implantation. J Am Coll Cardiol 2012, 60:493-501.

24. Epstein AE, DiMarco JP, Ellenbogen KA, Estes NA 3rd, Freedman RA, Gettes LS, Gillinov AM, Gregoratos G, Hammill SC, Hayes DL, Hlatky MA, Newby LK, Page RL, Schoenfeld MH, Silka MJ, Stevenson LW, Sweeney MO, American College of Cardiology/American Heart Association Task Force on Practice; American Association for Thoracic Surgery; Society of Thoracic Surgeons: ACC/AHA/HRS 2008 Guidelines for Device-Based Therapy of Cardiac Rhythm Abnormalities: a report of the American College of Cardiology/ 
American Heart Association Task Force on Practice Guidelines (Writing Committee to Revise the ACC/AHA/NASPE 2002 Guideline Update for Implantation of Cardiac Pacemakers and Antiarrhythmia Devices) developed in collaboration with the Association for Thoracic Surgery and Society of Thoracic Surgeons. J Am Coll Cardiol 2008, 51:e1-62.

25. Erkapic D, Kim WK, Weber M, Möllmann H, Berkowitsch A, Zaltsberg $S$, Pajitnev DJ, Rixe J, Neumann T, Kuniss M, Sperzel J, Hamm CW, Pitschner HF: Electrocardiographic and further predictors for permanent pacemaker requirement after transcatheter aortic valve implantation. Europace 2010, 12:1188-1190

26. Walther T, Falk V, Kempfert J, Borger MA, Fassl J, Chu MW, Schuler G, Mohr FW: Transapical minimally invasive aortic valve implantation; the intitial 50 patients. Eur J Cardiothorac Surg 2008, 33:983-988.

doi:10.1186/1471-2261-12-87

Cite this article as: Akin et al:: Predictive factors for pacemaker requirement after transcatheter aortic valve implantation. $B M C$ Cardiovascular Disorders 2012 12:87.

\section{Submit your next manuscript to BioMed Central and take full advantage of:}

- Convenient online submission

- Thorough peer review

- No space constraints or color figure charges

- Immediate publication on acceptance

- Inclusion in PubMed, CAS, Scopus and Google Scholar

- Research which is freely available for redistribution 